\title{
Ciliopathies: Primary Cilia and Signaling Pathways in Mammalian Development
}

\author{
Carmen Carrascosa Romero ${ }^{1}$, José Luis Guerrero Solano² \\ and Carlos De Cabo De La Vega ${ }^{3}$ \\ ${ }^{1}$ Neuropediatrics, \\ ${ }^{2}$ Neurophsyology and \\ ${ }^{3}$ Neuropsychopharmacology Units, Albacete General Hospital \\ Spain
}

\section{Introduction}

\subsection{Ciliopathies, an emerging class of human genetic diseases}

The physiological role of motile cilia or flagella in cell locomotion, sexual reproduction and fluid movements is well known. In 1898, the Swiss anatomist KW Zimmerman first described cilia on the surface of mammalian cells, for which he suggested a sensory role. His findings were largely ignored until the late 1960s, when Wheatley, using the electron microscope, stumbled upon a properly sized bubble in his histological preparation, verifying it as the cilium described by Zimmerman 63 years earlier[1]. Although it became known that all cells, from green alga Chlamydomonas to human cells - especially kidney cells- possessed a nonmotile cilium, it was initially considered a vestigial structure with no clear function.

Recent discoveries have assigned novel functions to primary (nonmotile) cilia, ranging from mechanosensory in maintaining cellular homeostasis, to participation in signal transduction pathways that regulate intracellular $\mathrm{Ca} 2+$ levels. Furthermore, the cilium is now emerging as an essential organelle in morphogenesis, important to key developmental pathways such as Sonic Hedgehog (Shh) and Wnt (planar cell polarity (PCP) pathways). The function of nodal cilia, for example, is vital for breaking early embryonic symmetry, Shh signaling is important for tissue morphogenesis and successful Wnt signaling for organ growth and differentiation. Defects in cilia formation or function have profound effects on anatomical development and the physiology of multiple organ systems such as death of photoreceptors, kidney tubule cysts, extra limb digits and brain malformation [2,3]. Alterations in ciliary function also play a role in specific organ diseases (polycystic kidney disease, pigmentosa retinitis...) and pleiotropic phenotypes (Bardet-Bield Syndrome, Alstrom S., Meckel-Gruber S., Oro-Facio-Digital S...), until recently of unknown origin. Our greater knowledge of genetics and the recognized role of cilium in morphogenetic signaling pathways, especially in neurogenesis, bring Bronowski's phrase "All science is the search for unity in hidden likenesses" to life [4]. 


\section{Histology}

\subsection{Cilium structure}

The cilia are organelles extending from the eukaryotic cell surface, similar to hair. The cilia are short and flagella are long, yet they share the same structure in all eukaryotes $[5,6]$. The primary cilium emerges from one of the centrioles, a basal body (a modified centriole) formed by 9 triplets of microtubules. The basal body is the microtubule organizing center derived from the oldest of the pair of centrioles and controls the movement of cilia and flagella. During interphase the distal end of the older centriole in the centrosome attaches to and becomes enclosed by a membrane vesicle. The microtubule core of the cilium (the axoneme) then assembles directly onto the microtubules of the centriole. As the axoneme lengthens, the primary ciliary vesicle enlarges and becomes a sheath. With time, the sheath (ciliary membrane) fuses with the cytoplasmic membrane and the primary cilium protrudes from the cell surface.

Microtubules are double and parallel (A complete, B incomplete), and are linked by nexin bridges. Some cilia also contain a pair of central single microtubules, called the central pair, involved in regulating motility, surrounded by a sheath and linked by bridges. Thus the types of cilia are classified as follows (TABLE 1):

- Motile: Axonemes: the $9+2$ Pattern (with central pair).

- Sensory, primary or immotile: Axonemes 9+0 Pattern (no central pair).

Defects in any of these structures can lead to ciliary diseases, and symptoms depend on the target structure.

Ciliary motility is accomplished by dynein motor activity, which slides the microtubule doublets relative to one another. At its base, the ciliary axoneme extends from the nine triplet microtubules of the basal body. Motility is provided by two sets of dynein arms, internal and external, emerging from a doublet of the $A$ microtubule and going to the $B$ microtubule of the following doublet. It is regulated by a 9-spoke (radial spoke) interacting with the central pair from the A microtubule. [7].

Hundreds of proteins are required for cilia formation and function, which is essential for $\mathrm{Hh}$ signaling in mammals, therefore these proteins could influence the Hh signal transduction. If this is proven, the challenge will be to understand the physical relationships between components and the Hh pathway that allow efficient ciliary Hh signaling [8,9]. Ciliary abnormalities fall into four major categories: 1) cilia with abnormal axial microtubules; 2) compound cilia; 3) swollen cilia; and 4) cilia with dynein arm defects.

\subsection{Cilium functions: The role of cilia in cell physiology}

The different functions of cilia are a reflection of their structural diversity, even within the same body. These functions are involved in regulating critical cellular processes:

1. Motility.

2. Polarization of cell division: Cell cycle and cytoskeletal organization.

3. Intraflagelar transport (IFT).

4. Reception and transduction of extracellular signals: These sensory organelles act as cellular signaling systems: as antenna for reception and transduction of extracellular molecular signals [10], and as physiological ligands into the cell [11]. They have crucial roles in several signal transduction pathways such as: Hedgehog $(\mathrm{Hh})$ signaling in gene transcription (morphogenic signal) and cell differentiation regulation; Wnt (canonical 
Wnt and noncanonical Wnt), planar cell polarity (PCP) and platelet-derived growth factor (PDGF) pathways.

\begin{tabular}{|c|c|c|}
\hline & MOTILE CICLIA & PRIMARY CILIA \\
\hline AMOUNT & 1 to billions per $\mathrm{cm}^{2 *}$ & 1 \\
\hline ESTRUCTURE & $\begin{array}{l}9+2 \\
\text { a) respiratory epithelium }\end{array}$ & $\begin{array}{l}9+0 \\
\text {-motile: b)nodal cells. } \\
\text {-non motile: } \\
\text { c) renal cells } \\
\text { d) olfactory cells } \\
\text { e) connecting segment, photoreceptor } \\
\text { f) balance system kinocilia with the } \\
\text { stereocilia. }\end{array}$ \\
\hline MOTILITY & MOTILE & NON MOTILE \\
\hline \multirow[t]{2}{*}{ FUNCTION } & $\begin{array}{l}\text { CELL MOTION OR } \\
\text { EXTRACELULLAR FLUIDS. }\end{array}$ & SENSORY \\
\hline & “SWEEP" & "ANTENNAE" \\
\hline DISEASE & $\begin{array}{l}\text { Early embyo death. } \\
\text { Respiratory dysfunction } \\
\text { (bronchiectasis, sinusitis). } \\
\text { Situs inversus. Reproductive } \\
\text { sterility. Hydrocephalus. }\end{array}$ & $\begin{array}{l}\text { LIMB DEVELOPMENT: morphogenetic } \\
\text { signals: polydactyly } \\
\text { NEURALTUBE: Gastrulation and } \\
\text { Neurulation movements } \\
\text { RETINA: retinitis pigmentosa } \\
\text { KIDNEY: PDK, nephronophthisis. } \\
\text { PDK and retinal degeneration. } \\
\text { COGNITIVE IMPAIRMENT } \\
\text { CILIA GLOBAL DISFUNCTION, } \\
\text { PLEIOTROPIC HUMAN DISEASES: } \\
\text {-Z-BIEDL SYNDROME (BBS) } \\
\text {-ALSTRÖM SYNDROME (ALMS) } \\
\text {-OROFACIODIGITAL 1 SYNDROME } \\
\text {-MECKEL-GRUBER SYNDROME } \\
\text {-JOUBERT SYNDROME } \\
\text {-ELLIS-VAN CREVELD SYNDROME } \\
\text {-ASPHYXIATING THORACIC } \\
\text { DYSTROPHY, JEUNE SYNDROME }\end{array}$ \\
\hline
\end{tabular}

Table 1. Cilia types

\section{Motility: Agents of cellular movement}

Cilia also generate mucus flow and cerebrospinal fluid [12], and can act as mechanosensors and flow meters. Many studies have demonstrated motility as one of the main functions of cilia, and its impairment may cause severe phenotypes such as decreased ciliary beat frequency in the respiratory epithelium [13]. Ciliary motility is also required for brain development and function. The ependymal motile 9+2 cilia are responsible for ependymal 
flow; ciliary motility loss leads to reduced fluid flow in brain ventricles, resulting in hydrocephalus $[14,15,16]$

Motility is the main feature of the unique $9+0$ primary cilium at the embryonic node, which is essential for correct embryonic development. Impairment of these cilia result in embryos showing randomized left-right asymmetry and randomized turning and heart looping [17

\section{Cell cycle: Centriole union link}

Polarization of cell division: Recent advances have demonstrated that ciliary proteins are involved in the regulation of the cell cycle. Centrioles play a dual role in the cell. They form the centrosomes that can interconvert with basal bodies upon ciliation. At the same time, they also give rise to the poles of the mitotic spindle. Centrioles may function as a signaling platform, through proteins that promote the transition from one phase to another in mitosis [18].

- Apc2, anaphase promoting complex protein 2

- $\quad$ Platelet-derived growth factor receptors (Pdgfr)

The Centrosome is an organelle located in the center of eukaryotic cells, and acts as an organizing center rather than a microtubule [19]. The centrosome is known as the cytoskeleton's microtubule organizing center of the eukaryotic cell animal, that radiates in a star way or ASTER during mitosis. Experiments show that centrosome absence prevents the cytogenesis process; the cycle does not progress beyond G1.

The centrosome consists of: a) the Diplosome, two cylindrical centrioles arranged perpendicularly, located near the nucleus (9 groups of 3 microtubules in cylindrical provision, diameter of $200 \mathrm{~nm}$ and $400 \mathrm{~nm}$ long). The centrioles of the centrosome are distinguished by a Mother centriole (mature) and a Daughter one; the Mother centriole is associated with proteins forming appendices: distal (related to cilia and flagella; a centriole at the base of each cilium or flagellum) and subdistal, involved in microtubule nucleation. b) the pericentriolar material, the dense part of the cytosol (amorphous-looking material) and c) the aster fibers (microtubules organized in rays).

The centrosome's main function is to form and organize the microtubules that comprise the achromatic spindle in division of the cell nucleus. The paternal centrosome plays the motor role in meiosis, while the maternal centrosome disappears. Only the mature mother centriole, likely due to the existence of subdistal appendages, transforms into the peculiar structure at the distal end, the basal body, which gives rise to the cilia and flagella of eukaryotic cells. If certain factors are absent (the ODF2 in mice), the cells are unable to organize cilia or flagella [20].

The centrioles are surrounded by an electron-dense matrix called the pericentriolar material (PCM), composed of sets of proteins that modulate or assist in centrosome involving processes. To this day, genome sequencing and comparison has detected and described about 300 proteins that most likely work with the centrosome, although few of them are well known.

Mutations in intraflagellar transport (IFT) genes have clearly demonstrated a correlation between primary cilia and cell cycle control. The basal body-centrosome complex also plays a crucial role in coordinating IFT and the formation of cilia. The centrosome is surrounded by pericentriolar material (PCM), which serves as a nucleation site for microtubules. In 
mammalian cells, RNAi knockdown of a protein important for PCM organization, pericentrin, inhibits ciliogenesis and reduces the abundance of IFT components near the centrioles [21]. Mutations in a Drosophila pericentrin-like homolog also cause malformations in sensory neuron cilia and sperm, indicating that the pericentrin-mediated interaction between centrosomal and IFT proteins is evolutionarily conserved [22]. Misregulation of cell cycle control is at the basis of oncogenesis. The cancer-promoting proteins Aurora A and HEF1/NEDD9/CAS-L play a role in primary cilium stabilization. Loss of cilia in cancer may contribute to the insensitivity of cancer cells to environmental repressive signals [23].

\section{Intraflagellar transport protein system (IFT)}

During ciliogenesis, cilia elongate from the basal body by the addition of new axonemal subunits to the distal tip. As protein synthesis does not occur in cilia, axonemal and membrane components are conveyed in non-membrane-bound macromolecular particles by intraflagellar transport (IFT) along the axonemal microtubule doublets [24].

The proteins are transported as convoys, bringing together several proteins called "IFT particles". IFT have 2 transport routes [25, 26]:

- $\quad$ anterograde transport, from the cytoplasm to the outside and

- retrograde transport, from the tip of the cilium to the interior.

At the tip of the cilium there is a particular structure where there is a change in intraciliar transport direction [27 a 29]. Large IFT particles move between the axoneme microtubule doublets and ciliary membrane, transported by specific Golgi vesicles directed toward the ciliary pore complex using cytoplasmic dynein. These vesicles exocyst at the base of the cilium, where kinesin II transports the particles up to the tip. By shortening or recycling of the cilium, the IFT descend to the base by means of dynein 2 for recycling [31]. IFT play a key role in ciliogenesis, taking axoneme components synthesized in the cytoplasm to the tip of the cilium.

Intraciliar or intraflagellar transport is responsible for cilia growth, for renewal of its components and for the particular formation of the cilium membrane that distinguishes it from the rest of the plasma membrane [30].

\section{Hedgehog pathway}

The process and transfer of information signals to the cell are mediated by specialized proteins [3]:

- Cationic channels compounds by polycystin proteins Pc1 and Pc2 in the ciliary membrane are sensitive to mechanical stimuli.

- $\quad$ Platelet-derived growth factor receptors (Pdgfr), sensitive to extracellular ligands.

- $\quad$ Smoothened Receptors (Smo) [32]: The nodal point of life.

- Several microtubule-associated protein complexes that include proteins associated with nephronophthisis [NPHP, investment (Invs)], and with Bardet-Biedl syndrome (BBS).

Hedgehog proteins $(\mathrm{Hh})$ are a group of signaling proteins generating extracellular ligands that play an important role in regulating cell differentiation. In humans, there are three known Hedgehog proteins: Sonic Hh (Shh), Indian Hh and Desert Hh. When these ligands bind to various specific receptors, they trigger a signaling cascade resulting in activation of transcription factors of the Gli family that regulate the transcription of effector genes. The Hh receptors in vertebrates are the integral membrane "Patched" proteins Ptc1 and Ptc2 . 
The 1st step in the Hh signaling process is the physical union with Ptc, activating the pathway and producing internalization by endocytosis of the Hh-Ptc complex and its subsequent lysosomal degradation. This eliminates the extracellular morphogen and sets the concentration gradient.

- The transduction system involves Smoothened (Smo), a transmembrane protein. The Hh to Ptc union begins its internalization and releases Smo that, from intracellular vesicles, shifts and accumulates on the cell surface where it is translocated to the cilia, initiating the signaling cascade that culminates in the modulation of the transcription factors Ci / Gli (Gli protein 1, 2 and 3) [33, 34]

\subsection{Embryonic development}

The Hedgehog $(\mathrm{Hh})$ pathway determines growth patterns and embryonic differentiation in a large number of organs. Approximately half of all mutations affect the initial establishment of the body plan, and several of these produce phenotypes that have not been described previously. A large fraction of the genes identified affect cell migration, cellular organization, and cell structure. Findings indicate that phenotype-based genetic screens provide a direct and unbiased method for identifying essential regulators of mammalian development [35]. The mutant cilia are short, with a specific defect in the structure of the ciliary axoneme [36].

- The Hh signaling pathway is essential in embryogenesis due to its involvement in the development of multiple organs where it controls such important aspects as specification of different kinds of cells, cell proliferation and cell survival (apoptosis control).

- The ligand Shh (Sonic hh) is responsible for the functions of the best characterized development signaling centers such as the notochord and the zone of polarizing activity (ZPA) of the tip [37].

- The morphogen concentration provides cells with positional value commensurate with gradient position, determining cell destiny, generating an appropriate pattern or morphology, and foreshadowing the final organ or tissue pattern. Hh proteins act as morphogens in the development of the central nervous system, limbs, heart, blood vessels, gonads, intestine and kidney. In vertebrates, cilia also function in the Shhdependent patterning of the developing neural tube and limb [38]. Mutant mice with defects in ciliogenesis resulting from mutations in IFT protein-encoding genes, such as polaris, wimple (Ift172), Ngd5 (Ift52) and the gene encoding the retrograde motor Dnchc2, have neural tube defects and preaxial polydactyly phenotypes similar to mutants with defects in Shh pathway proteins [33, 39 a 42].

\subsubsection{Hh and limb development}

Cilia are present in the forebrain neurectoderm and in ectodermal and mesenchymal cells of the limb, but are aberrant or absent from these tissues in IFT mutants [33, 41, 42]. The zone of polarizing activity (ZPA), a small cluster of mesodermal cells located at the rear edge of the developing limb, is responsible for the anteroposterior pattern of the limb by secreting Shh, the morphogen controlling the number and identity of the fingers plus antero-posterior specification. The normal expression of Shh in chicken wing ZPA is accompanied by its diffusion gradient model scheme along the anteroposterior axis. Normal skeletal pattern of the chicken wing consists of 3 digits known as $2(\mathrm{~d} 2), 3(\mathrm{~d} 3)$ and $4(\mathrm{~d} 4)$. 
Formation of finger-type depends on morphogen levels to which precursor cells were subjected during development. When another source of Shh is introduced at previous levels, either naturally or through experimental means, two gradients are generated in the outline of the limb which, depending on their geometry, may overlap with each other in the central area of the limb. This configuration leads to mirror duplications of the digits (d4-d3-d2-d3d4) [41].

\subsubsection{Hh and central nervous system development}

In the developing mammalian ventral spinal cord, five different neuronal cell types, comprising the motoneuron ( $\mathrm{MN}$ ) and four different interneurons (V0-V3), are generated from their respective neural progenitors ( $\mathrm{pMN}, \mathrm{pV0}-\mathrm{pV3})$ under the influence of signals from the notochord [43]. Shh, one of the Hedgehog (Hh) family of proteins, is strongly expressed in the notochord and later in the floor plate, and is able to mimic the ability of the notochord for inducing different ventral spinal cord cell types. In response to Shh signaling, neural progenitors activate or suppress the expression of several homeobox and basic helixloop-helix (bHLH) transcription factors. The combinatorial expression of these transcription factors defines the fate of the neural progenitor cells [44].

Although Shh has been shown to be sufficient for the induction of distinct ventral spinal cord neurons, recent studies have suggested an alternative derepression mechanism whereby many neuronal cell types could be generated in the absence of Shh signaling. For example, although most of the ventral cell types are absent from Shh or Smo mutants because of the ectopic production of Gli3 repressor, most of the ventral neurons are generated in Shh; Gli3 and Smo;Gli3 double mutants [45,46]. Similarly, in embryos that lack all Gli transcription factors and cannot respond to Hh signaling, many of the ventral neurons are also present $[47,48]$. These results suggest that perhaps the primary role of $\mathrm{Hh}$ signaling is to repress excess Gli3 repressor in the ventral spinal cord so that progenitors can respond to other signals. An additional role for Shh signaling is to organize the formation of distinct progenitor domains, as different cell types intermix in the absence of Shh signaling [49].

The mouse mutation, hennin (hnn), causes coupled defects in cilia structure and Sonic hedgehog (Shh) signaling. Gli3 repressor activity is normal in hnn embryos, but Gli activators are constitutively active at low levels. The hnn phenotypes are whole e10.5 wildtype (A) and hnn (B and C) embryos, which show exencephaly and spina bifida. As a result, IFT mutants display a loss of Hh signaling phenotype in the neural tube, where Gli activators play the major role in pattern formation, and a gain of Hh signaling phenotype in the limb, where Gli3 repressor plays the major role. Because both anterograde and retrograde IFT are essential for positive and negative responses to $\mathrm{Hh}$, and because cilia are present on Hh responsive cells, it is likely that cilia act as organelles that are required for all activity of the mouse Hh pathway [50].

During development of the central nervous system, Shh secreted in the prechordal plate, notochord and floor plate, disseminates and establishes a concentration gradient across the dorsal ventral axis of the neural tube, with maximum levels at the ventral side, forming an appropriate dorsoventral pattern of cell differentiation. Finally, mediated by the three Gli transcription factors' combined activity, Shh, in the neural tube, not only controls the specification but also regulates cell proliferation and survival through cell cycle regulation 
and expression of antiapoptotic genes. Moreover, the neocortex, cerebellum and tectum growth also depend on the mitogenic activity of Shh [51 a 55]. Recently, it has been attributed a role in axonal growth [56], and in maintaining stem cell niches in the adult.

\subsection{Stem cell proliferation and differentiation: neurogenesis}

In adults, the Hh signal is involved in maintaining stem cell and tissue homeostasis. In neurogenesis, the brain's mature CM receives signals to divide and differentiate into neurons. The primary cilium plays a key role in the $\mathrm{CM}$ receiving orders to divide by the uptake of cell growth factors through the route called "Sonic hedgehog".

Degenerative defects:

Neural stem cells (NSCs) are present in the mammalian brain from embryo to adult. It has been shown that these cells are a significant source of new neurons, and promise to be the origin of a new central nervous system restorative therapy: Hedgehog $(\mathrm{Hh})$ signaling is involved in a wide range of important biological activities. Within the vertebrate central nervous system, Sonic Hedgehog (Shh) can act as a morphogen or mitogen that regulates the patterning, proliferation, and survival of neural stem cells (NSCs). However, its role in embryonic stem cell (ESC) neurogenesis has not been explored in detail. Hh signaling is required for ESC neurogenesis; in order to elucidate the underlying mechanism, Cai C. et al [57] utilized the Sox1-GFP ESC line, which has a green fluorescent protein (GFP) reporter under the control of the Sox1 gene promoter, providing an easy means of detecting NSCs in live cell culture. That ESC differentiation in adherent culture follows the ESC--> primitive ectoderm --> neurectoderm transitions observed in vivo. Selective death of the Sox1-GFPnegative cells contributes to the enrichment of Sox1-GFP-positive NSCs. Interestingly, Shh is expressed exclusively by the NSCs themselves and elicits distinct downstream gene expression in Sox1-GFP-positive and -negative cells. Suppression of Hh signaling by antagonist treatment leads to different responses from these two populations as well: increased apoptosis in Sox1GFP-positive NSCs and decreased proliferation in Sox1-GFP-negative primitive ectoderm cells. Hedgehog agonist treatment, in contrast, inhibits apoptosis and promotes proliferation of Sox1-GFP-positive NSCs. These results suggest that $\mathrm{Hh}$ acts as a mitogen and survival factor during early ESC neurogenesis, and evidence is presented to support a novel autocrine mechanism for Hh-mediated effects on NSC survival and proliferation.

An intravenous $\mathrm{Hh}$ agonist at doses that upregulate spinal cord Gli1 transcription also increases the population of neural precursor cells after spinal cord injury in adult rats. These data support previous findings based on injections of Shh protein directly into the spinal cord [58].

A common feature of embryonic and adult NSCs is that they have a primary cilium emerging from a mother centriole, and through its receptors Sonic Hedgehog (Shh) is involved in cell specification and neurogenesis with neural progenitors' expansion in brain development [59]. Shh is active in some groups of cells in mature organs which seem to be involved in maintaining stem cell numbers.

In mammalian telencephalon, two postnatal neurogenesis areas are known: the hippocampus dentate gyrus and the telencephalic ventricles' subventricular zone. Quiescent cells express low levels of Gli1, a marker of responding Shh cells, but the Shh/Gli pathway is activated to regulate the generation of new neurons [60]. The Shh signaling cascade is also involved in the maintenance of other types of adult stem cells such as hematopoietic cells [61]. 


\subsection{Oncology and carcinogenicity}

Recently, many vertebrate-specific components have been identified that act between the GOS and Gli. These include intraflagellar transport proteins which link vertebrate $\mathrm{Hh}$ signaling to cilia. Because abnormal Hh signaling can cause birth defects and cancer, these vertebrate-specific components may play a role in human health. Hh signaling has been involved in development of several human cancers including small cell lung carcinoma, medulloblastoma, basal cell carcinomas, digestive tract (pancreas) tumors, brain, prostate, skin, etc. [62 a 67].

PTC has been considered a tumor suppressor gene: Ptc inhibits the signaling pathway, so the loss of activity results in activation of the Shh pathway.

Many oncogenic factors may converge on Gli activity to promote tumor progression, thus pointing towards the Hh signaling cascade as a phenomenon to be considered in potential treatments for many different types of cancer. For example, Gorlin syndrome or nevoid basal cell carcinoma syndrome is caused by a disorder of chromosome 9 (q22.3 and q31) and 1 (p32), leading to mutations in the PTCH tumor suppressor gene, a human homologue of Drosophila melanogaster patched gene. The PTCH gene encodes the signal's Sonic Hedgehog (Shh) transmembrane protein receptor, a regulatory molecule in embryogenesis and carcinogenesis [68].

\section{Wnt Signaling pathways}

There are 3 known pathways, activated after docking of Wnt to its "Frizzle" family receptors (FZD) (See Gerdes JM y Katsanis N. 2008 review[69]):

\subsection{Canonical wnt pathway}

It acts through $\beta$-catenina/Arm and specifies different cell types, controlling proliferation and apoptosis depending on the development context. It is activated in virtually all tumors. Induces stabilization and accumulation in the cytoplasm of $B$-catenin and its subsequent translocation to the cell nucleus where it affects transcription of target genes [2, 3, 70, 71].

a. When the Wnt signal is not activated, $B$-catenin binds to the degradation complex consisting of APC axin and the serine/threonine kinases CK1 and GSK3. The degradation complex's main role is to phosphorylate B-catenin, guiding it to its degradation through addition of multiple ubiquitins and its enzymatic process in the proteasome. There are several negative regulators operating at the ligand receptor-like level, such as Cer1, DKK, and sFRP, whose function is to modulate Wnt-induced positive signals.

b. Wnt contact with its receptors leads to stabilization of B-catenin and its accumulation in the cytoplasm. B-catenin displaces Groucho transcriptional repression from the complex formed by LEF/TCF, leading to activation of target genes such as C-MYC and CCND1, which are involved in cell cycle progression and proliferation.

c. Canonical Wnt signaling is involved in the generation of different cell types in the ventral spinal cord: The identity of distinct cell types in the ventral neural tube is generally believed to be specified by sonic hedgehog (Shh) in a concentration-dependent manner. However, recent studies have questioned whether Shh is the sole signaling molecule determining the fate of ventral neuronal cells. There is evidence showing that canonical Wnt signaling is involved in the generation of different cell types in the ventral spinal 
cord. Wnt signaling is active in the mouse ventral spinal cord at the time when ventral cell types are specified. Furthermore, using an approach that stabilizes beta-catenin protein in small patches of ventral spinal cord cells at different stages, Wnt signaling activates different subsets of target genes depending on the time when Wnt signaling is amplified. Moreover, disruption of Wnt signaling results in the expansion of ventrally located progenitors. Finally, Wnt signaling interacts with Hh signaling at least in part through regulating the transcription of Gli3. Yu W. et al [72] reveal a novel mechanism by which ventral patterning is achieved through coordination of Wnt and Shh signaling.

\subsection{The planar cell polarity pathway (PCP)}

Sets the polarization of the cells along the plane of a tissue membrane. This pathway is important for neural tube closure and cochlear extension of the inner ear. Is involved in cell polarity, tissue and cell movement processes.

\subsection{WNT/CA+2 OR "Non-canonical" pathway}

Regulates cell adhesion and motility mediated by Wnt-5a, triggers intracellular Ca2+ release to activate $\mathrm{Ca} 2+$-sensitive enzymes such as protein kinase $\mathrm{C}$ (PKC ), calmodulin-dependent kinase II and $\mathrm{Ca} 2+(\mathrm{CaMKII})$ without $ß$-catenin pathway activation.

\section{Ciliary dysfunction: Human phenotypes}

Given the multiple roles of cilia in development and physiology, it is not surprising that defects in cilia cause multiple human diseases (reviews see Afzelius, 2004 [73]; Badano et al., 2006 [74]; Fliegauf et al., 2007 [75]; Quinlan RJ et al, 2008 [2]; D'Angelo A. et al, 2009 [76])

Perhaps the most puzzling aspect of ciliopathies is that different ciliary diseases involve different, often partially overlapping sets of symptoms. For instance, Bardet-Biedl patients suffer from obesity, retinal degeneration, and cystic kidneys, whereas Oral-Facial-Digital syndrome patients suffer from polydactyly and cystic kidneys. However, both types of diseases result from defects in genes whose protein products localize to the ciliary basal body. Why don't all ciliary defects produce the same set of symptoms? The key to this question is to realize that despite the growing wealth of genomic and proteomic data on cilia composition [77], cilia are not just lists of genes but complex organelles with variable ultrastructures that must assemble and function in different tissue contexts. Why might defects in two cilia-related genes lead to distinct diseases? There are several ways this can happen: (1) some ciliary genes may have additional cilia-unrelated gene functions; (2) some mutations may affect the ciliogenesis of only a subset of all cilia in the body; and (3) genetic defects may affect different ultrastructural modules of cilia and, thus, only influence a subset of ciliary functions [78].

\subsection{Cilia motility dysfunction}

- Major clinical features:

- Early embryo death.

- Respiratory dysfunction (bronchiectasis, sinusitis).

- Reproductive sterility.

- Hydrocephalus 
- Embryo symmetry. Nodal cilia: It has been proven that nodal ciliary flow is required to generate the right/left symmetry axis. Between days 10 and 25 of embryonic development, a sophisticated biochemical reaction cascade determines that the human body will be: asymmetrical inside -with the heart on the left and liver on the right; and symmetrical outside -with two hands, two feet and the navel in the middle. Stem cells that become different body tissues enter the node (cells that direct embryo growth). The node has hundreds of cilia (nodal cilia) that guide each cell to its destination in the embryo. Nodal cilia run in subtle circular motion, creating convection currents in the fluid where the embryo is immersed (nodal flow). These currents help to carry the cells to their proper place. FoxJ1 transcription factor is the master key to the formation of nodal cilia, which are responsible for left-right asymmetry [79 a 81].

- Primary ciliary dyskinesia (PCD): is a rare autosomal recessive disease (GENE: DNAHC11, locus:7p21), characterized by abnormal ciliary structure and function. The ciliary defect is a result of absence or anomalies of dynein arms and pairs of microtubule structures responsible for movement. Patients show recurrent lung, sinus and middle ear infections. Male infertility may be present, due to immotile sperm. Female fertility is also affected, given the presence of cilia in the fallopian tubes and fimbriae. Kartagener syndrome (50\%) is associated with situs inversus [ 82 a 85 ].

- Hydrocephalus appears to be specifically associated with defects in the central pair of microtubules as typified by the mouse hydin mutant, which has hydrocephalus and lacks the central pair. Ciliary motility is necessary for brain development and function; the "ependymal flow" is required to maintain an open aqueduct $[86,87]$.

\subsection{Sensory cilia dysfunction (cilium)}

Given the many roles of cilia in physiology and development, it is not surprising that its defects cause multiple human diseases. Perhaps cilia's most enigmatic aspect is that only one defect involves different diseases, often with a partially overlapping set of symptoms [2]. High ranked phenotypes by: $1^{\circ}$ the necessary ubiquitous presence in each of the cell types of the human body, and $2^{\circ}$ the emerging role in morphogenetic signal transduction. (TABLE 2).

- Development of limbs: morphogenetic signals: Polydactyly

- Neural tube: movements during gastrulation and neurulation

- Retina: Retinitis Pigmentosa, retinal blindness

- Kidney: PKD y Nephronophthisis.

- $\quad$ PKD and retinal degeneration (Senior-Loken Syndrome)

- Cognitive impairment

Retina: photo-receptors: have a primary cilium $(9+0)$ that connects the outer segment (rhodopsin disks) to the inner segment where rhodopsin is synthesized. Molecules that detect light are synthesized in the inner segment and must be transported to the outer segment by intraciliar transport. Mutations in a gene involved in transport of these molecules needed for seeing or outer segment maintenance result in degeneration of photoreceptors leading to blindness such as in retinitis pigmentosa. Dysfunction of primary cilia due to mutations in cilia-centrosomal proteins is associated with pleiotropic disorders. The primary (or sensory) cilium of photoreceptors mediates polarized trafficking of proteins for efficient phototransduction. Retinitis pigmentosa GTPase regulator (RPGR) is a cilia-centrosomal protein mutated in $>70 \%$ of X-linked RP cases and $10 \%-20 \%$ of simplex RP males. Accumulating evidence indicates that RPGR may facilitate the orchestration of 
multiple ciliary protein complexes. Disruption of these complexes due to mutations in component proteins is an underlying cause of associated photoreceptor degeneration. Here, we highlight the recent developments in understanding the mechanism of cilia-dependent photoreceptor degeneration due to mutations in RPGR and PGR-interacting proteins in severe genetic diseases, including retinitis pigmentosa, Leber congenital amaurosis (LCA), Joubert syndrome, and Senior-Loken syndrome. Additionally, we explore the physiological relevance of photoreceptor ciliary protein complexes [88, 89].

\begin{tabular}{|l|l|}
\hline 1 & Dandy-Walker Syndrome \\
\hline 2 & Corpus callosum agenesis \\
\hline 3 & Situs inversus \\
\hline 4 & Posterior Encephalocele \\
\hline 5 & Renal cystic disease \\
\hline 6 & Postaxial polydactyly \\
\hline 7 & Liver disease \\
\hline 8 & Retinitis Pigmentosa \\
\hline 9 & Mental retardation \\
\hline
\end{tabular}

Table 2. Clinical features that may predict cilia involvement (listed by relevance) From: Badano JL, et al [74]

RENAL: Polycystic kidney disease (PKD) [90], and Nephronophthisis [91]. PKD is the most common inherited disease in the United States. Current estimates are that 600000 patients have PKD in the US, with 12.5 million cases worldwide (for a recent, comprehensive review on PKD see [90]. The inherited PKDs include autosomal dominant type (ADPKD), autosomal recessive (ARPKD), and nephronophthisis. ADPKD, the most common form, occurs in 1 amongst 600-800 live births and affects 500000 persons in the US. The disease occurs during adult life and is characterized by extensive cystic enlargement of both kidneys. Of the two types of ADPKD, type I is caused by a mutation in the PKD1 gene, and type II by a mutation in the PKD2 gene [92]. The proteins encoded by both genes are transmembrane proteins. Polycystin 1 is proposed to be a cell-cell and cell- matrix adhesion receptor [93] and polycystin 2 is thought to act as a calcium-permeable membrane channel [94]. Polycystic kidney is the result of altered intraciliar transport of non-motile primary cilia of the renal tubule epithelial cells [95]. In PKD, cyst formation is associated with increased numbers of cells in the circumference of renal tubules. In mice with renal-specific inactivation of Tcf2, and in the pck rat, which has reduced expression of $P k d 2$ and/or $P k h d 1$, mitotic alignments along the axis of the tubules are significantly distorted, indicating a loss of PCP [96].

\section{Cognitive impairment}

Patients with ciliary dysfunction disorders display variably expressive brain dysgenesis as well as neurocognitive impairments. Joubert syndrome is a ciliopathy defined by cerebellar vermis hypoplasia, oculomotor apraxia, intermittent hyperventilation, and mental retardation. Recent evidence suggests important roles for the primary cilium in mediating a host of extracellular signaling events such as morphogen, mitogen, homeostatic and polarity signals. Based upon the clinical features of ciliopathies and cilia mediated signaling 
pathways, the data support a role for the primary cilium in modulating neurogenesis, cell polarity, axonal guidance and possibly adult neuronal function $[97,98]$.

\section{Global ciliary dysfunction in pleiotropic human diseases}

- $\quad$ BARDET-BIEDL (BBS) / OMIM: 209900

- $\quad$ ALSTRÖM (ALMS) / OMIM: 203800

- OROFACIODIGITAL TYPE 1/ OMIM: 311200

- JOUBERT SYNDROME / OMIM: 213300

- $\quad$ MECKEL-GRUBER / OMIM: 249000

- $\quad$ ELLIS - VAN CREVELD SYNDROME / OMIM: 225500

- $\quad$ ASPHYXIATING THORACIC DYSTROPHY, JEUNE SYNDROME /OMIM 208500.

Bardet-Biedl syndrome (BBS) or Laurence Moon-Biedl syndrome [99].

Retinal dystrophy, obesity, and polydactyly.

INHERITANCE: RA. Genes:12 BBS genes. Locus:11q13; 16q21; 3p12-q13; 15q22.3; 2q31; 20p12; 4q27; 14q32.11; 7p14; 12q; 9q33.1; 4q27.

PHENOTYPE: Obesity (83\%). Polydactyly, syndactyly, or both $(75 \%)$. Mental Retardation $(80 \%)$, spinocerebellar degeneration. Retinal degeneration: Retinitis pigmentosa $(68 \%)$ with night vision problems, loss of peripheric-central vision. By the age of 20,73\% are blind. Genital hypoplasia, hypogonadism (60\%). Renal cystic disease. Other: nystagmus, anosmia, asthma, diabetes insipidus, cardiac malformations and situs inversus.

\section{Alström (Alms) Syndrome}

INHERITANCE: RA; GENE: ALMS1; Locus:2P13. Protein: Alström syndrome protein 1.

PHENOTYPE: Obesity. Type 2 diabetes mellitus. Sensorineural hearing loss (cochlear neuronal degeneration). Photophobia and nystagmus (degeneration of photoreceptor cone cells). Others: short stature, cardiomyopathy, liver and renal failure, hypogonadism.

\section{Meckel-Gruber Syndrome}

INHERITANCE: RA. Genetic heterogeneity. 3 loci: MKS1 on 17q23, MKS2 on 11q13, MKS3 on $8 \mathrm{q} 21.13-\mathrm{q} 22.1$

PHENOTYPE: A fatal disease, characterized by: occipital encephalocele, bilateral renal cystic dysplasia, hepatic ductal dysplasia and cysts, and polydactyly.

Orofaciodigital syndrome 1

INHERITANCE: X-linked Dominant (fatal in males). GENE: OFD1; Locus: Xp22.3-p22.2. PROTEIN: Oral-facial-digital syndrome 1 protein.

PHENOTYPE: ORAL: Membrane between oral mucosa and alveolar bone. Partial clefts: upper lip, tongue, alveolar, palate. FACIAL: alar cartilage hypoplasia, short filter, hypertelorism with lateral location of inner edges. DIGITAL: asymmetric shortening of fingers (polydactyly / syndactyly). RENAL: renal microcysts. OTHER: Mental retardation (IQ 70), agenesis of the corpus callosum, cerebellar abnormalities and hydrocephalus, alopecia ...

\section{Joubert syndrome (JBTS)}

INHERITANCE: RA. 3genes: (AHI1, NPHP1, CEP290). Incidence: 1x100.000 NB. Affects the cerebellum (vermis hypoplasia) and brainstem; appears in neonatal period with a characteristic breathing pattern of tachypnea/apnea. 
PHENOTYPE: Head: macrocephaly, prominent forehead. Eyes: coloboma, nystagmus, strabismus, ptosis. Ears: low-set and thick. Nose: broad nasal bridge, epicanthus, anteverted nostrils. Open mouth, tongue protusion with rhythmic tongue movements. Neurological: generalized hypotonia, frog posture, hyperpnea followed by apnea. Ataxia. Other: polydactyly, seizures, scoliosis, congenital heart disease, pigmented retina. MRI: molar sign: There are 4 specific abnormalities: 1) Increased posterior interpeduncular fossa and decreased length of the isthmus. 2) Thick and elongated superior cerebellar peduncles in greater perpendicular orientation towards brainstem compared with normal orientation. 3) Hypoplastic or aplastic superior cerebellar vermis.4) Sagittal vermian cleft.

\section{Ellis-Van Creveld syndrome}

INHERITANCE: AR. GEN: two genes (EVC y ECV2). LOCUS:14p16. Protein: EVCS protein. Condroectodermal dysplasia, Mesoectodermal dysplasia. Incidence: $0.5 \times 100.000 . \quad 30 \%$ consanguineous. Common among the Pennsylvania Amish population.

PHENOTYPE: Acromesomelic dwarfism resulting in disproportionately short limbs, predominantly in the lower limbs and most striking distally (farthest from central trunk or midline). Final height reached is between 109 to $155 \mathrm{~cm}$. Postaxial polydactyly in hands and, occasionally, feet. Carpal and pastern bones fusion. Cleft lip at the junction of the upper hemi-lips, and labiogingival frenulum hypertrophy.

Congenital heart disease (50-60\%), septal defects, single atrium. Differential diagnosis with short rib-polydactyly syndromes: Jeune syndrome or asphyxiating thoracic dystrophy and oro-facio-digital syndrome.

Asphyxiating Thoracic Dystrophy, Jeune Syndrome.

INHERITANCE: RA. GENES: 2 (JATD1,JATD2). LOCI :15q13, 3q24-26. Protein: intraflagellar transport protein 80 homolog

PHENOTYPE: Retinal degeneration, kidney cysts, hepatic portal fibrosis, affecting infants who die of asphyxia in the neonatal period secondary to small chest with short ribs. Skeletal: Chondrodysplasia; shortness of long bones, hypoplastic iliac wings, conical epiphysis and phalangeal fusion. Polydactyly. OTHER: impaired pancreatic ...

\section{Conclusion}

Recent studies provide evidence for novel functions of primary cilia ranging from mechanosensory and cellular homeostasis, to signal transduction pathways that regulate intracellular $\mathrm{Ca}^{2+}$ levels. Their importance in key developmental pathways such as Sonic Hedgehog and Wnt is beginning to emerge. Defects in cilia formation or function have profound effects on the development of body pattern and the physiology of multiple organ systems. Thus, impairment of ciliar function is involved in organ specific diseases (e.g. polycystic kidney disease, retinitis pigmentosa) as well as pleiotropic syndromes (e.g. Bardet-Biedl, Alstrom, Meckel-Gruber and orofaciodigital syndromes) of unknown origin until recently. Increasing knowledge of the ciliar role in morphogenesis pathways in conjunction with genetic studies is helping to characterize a new group of diseases, previously unconnected to each other.

\section{References}

[1] Wheatley DN. Landmarks in the first hundred years of primary $(9+0)$ cilium research. Cell Biol Int. 2005; 29: 333-9. 
[2] Quinlan RJ, Tobin JL, Beales PL: Modeling Ciliopathies: Primary Cilia in Development and Disease. Current Topics in Developmental Biology, 2008; 84: 250-282

[3] BW, Yost HJ: The roles of cilia in developmental disorders and disease. Development. 2006; 133, 4131-4143

[4] Bronowski J. Science and human values (New York: Harper \& Row. 1965).

[5] Haimo LT, Rosenbaum JL: Cilia, flagella, and microtubules. The journal of cell biology. 1981; $91 \mathrm{n}^{\mathrm{o}} .3 \mathrm{pt}: 125 \mathrm{~s}-130 \mathrm{~s}$

[6] Afzelius B A: Cilia-related diseases. J. Pathol. 2004; 204: 470-477

[7] Sloboda R D: Intraflagellar transport and the flagellar tip complex. J. Cell Biochem. 2005; 94: 266-272

[8] Avidor-Reiss T. Maer A.M. Koundakjian E. Polyanovsky A. Keil T. Subramaniam S. et al.: Decoding cilia function; defining specialized genes required for compartmentalized cilia biogenesis. Cell. 2004; 117:527 -539.

[9] Li J. B. Gerdes J. M. Haycraft C. J., Fan Y. Teslovich, T. M. May-Simera et al: Comparative Genomics Identifies a Flagellar and Basal Body Proteome that Includes the BBS5 Human Disease Gene. Cell. 2004; 117: 541 -552

[10] Praetoriu H.A. and Spring K.R.: The renal cell primary cilium functions as a fl ow sensor. Curr. Opin. Nephrol. Hypertens. 2003; 12 : 517 - 520

[11] Christensen S.T. Pedersen L.B. Schneider L. Satir P: Sensory cilia and integration of signal transduction in human health and disease. Traffi c . 2007; $8: 97-100$

[12] Eggenschwiler J.T. Anderson K.V: Cilia and developmental signaling.Annu. Rev. Cell Dev. Biol. 2007; $23: 345-373$.

[13] Fernandez-Gonzalez A. Kourembanas S. Wyatt TA. Mitsialis SA: Mutation of murine adenylate kinase 7 underlies a primary ciliary dyskinesia phenotype. Am J Respir Cell Mol Biol. 2008; 40:305-313.

[14] Banizs B, Pike MM, Millican CL, Ferguson WB, Komlosi P, Sheetz J, Bell PD, Schwiebert EM, Yoder BK: Dysfunctional cilia lead to altered ependyma and choroid plexus function, and result in the formation of hydrocephalus. Development. 2005; 132:5329-5339.

[15] Ibanez-Tallon I, Pagenstecher A, Fliegauf M, Olbrich H, Kispert A, Ketelsen UP, North A, Heintz N, Omran H: Dysfunction of axonemal dynein heavy chain Mdnah5 inhibits ependymal flow and reveals a novel mechanism for hydrocephalus formation. Hum Mol Genet. 2004; 13:2133-2141.

[16] Eley L, Yates LM, Goodship JA: Cilia and disease. Curr Opin Genet Dev 2005; 15: 308314.

[17] Nonaka S, Tanaka Y, Okada Y, Takeda S, Harada A, Kanai Y, Kido M, Hirokawa N: Randomization of left-right asymmetry due to loss of nodal cilia generating leftward flow of extraembryonic fluid in mice lacking KIF3B motor protein. Cell 1998; 95:829-837.

[18] Linck R.W, Stephens R.W: Functional protofi lament numbering of ciliary, fl agellar, and centriolar microtubules. Cell Motil. Cytoskeleton. 2007; 64: 489-495

[19] Rieder CL, Faruki S, Khodjakov A. The centrosome in vertebrates: more than a microtubule-organizing center. Trends Cell Biol 2001; 11: 413-419.

[20] Dirksen, E.R. Centriole and basal body formation during ciliogenesis revisited. Biol. Cell. 1991; 72: 31 - 38 . 
[21] Jurczyk A, Gromley A, Redick S. San Agustin J, Witman G, Pazour G.J. et al: Pericentrin forms a complex with intraflagellar transport proteins and polycystin-2 and is required for primary cilia assembly. J. Cell Biol. 2004; 166, 637-643

[22] Martinez-Campos M, Basto R, Baker J, Kernan M, Raff J. W: The Drosophila pericentrinlike protein is essential for cilia/flagella function, but appears to be dispensable for mitosis. J. Cell Biol. 2004; 165, 673-683

[23] Plotnikova OV, Golemis EA, Pugacheva EN: Cell cycle-dependent ciliogenesis and cancer. Cancer Res 2008; 68: 2058-2061

[24] Kozminski KG, Johnson KA, Forscher P, Rosenbaum J L: A motility in the eukaryotic flagellum unrelated to flagellar beating. Proc. Natl.Acad. Sci. USA.1993; 90: 55195523

[25] Pazour GJ, Dickert BL, Witman GB. The DHC1b (DHC2) isoform of cytoplasmic dynein is required for flagellar assembly. J. Cell Biol. 1999; 144: 473-481

[26] Signor D, Wedaman K P, Orozco JT, Dwyer N D, Bargmann C I, Rose L S, et al: Role of a class DHC1b dynein in retrograde transport of IFT motors and IFT raft particles along cilia, but not dendrites, in chemosensory neurons of living Caenorhabditis elegans. J. Cell Biol. 1999; 147: 519-530

[27] Qin H, Burnette D T, Bae Y K, Forscher P, Barr M M, Rosenbaum JL: Intraflagellar transport is required for the vectorial movement of TRPV channels in the ciliary membrane. Curr. Biol. 2005; 15, 1695-1699

[28] Wang Q, Pan J, Snell WJ.: Intraflagellar transport particles participate directly in ciliumgenerated signaling in Chlamydomonas. Cell 2006; 125: 549-562

[29] Pedersen LB, Geimer S, Sloboda R D, Rosenbaum J L: The Microtubule plus endtracking protein EB1 is localized to the flagellar tip and basal bodies in Chlamydomonas reinhardtii. Curr. Biol. 2003; 13: 1969-1974

[30] Rosenbaum JL, WitmanGB: Intraflagellar transporte. Nat. Rev. Mol Cell Biol. 2002; Nov; 3 (11) :813-25

[31] Scholey JM. Intraflagellar transport motors in cilia: moving along the cell's antenna. J. Cell. Biol . 2008; 180: 23-29

[32] Corbit K C, Aanstad P, Singla V, Norman A.R, Stainier D Y, Reiter JF: Vertebrate Smoothened functions at the primary cilium. Nature 2005; 437: 1018 -1021

[33] Haycraft C J, Banizs B, Aydin-Son Y, Zhang Q, Michaud E J, Yoder B: KGli2 and Gli3 localize to cilia and require the intraflagellar transport protein polaris for processing and function. PLoS Genet. 2005; 1, e53.

[34] Dai P, Akimaru, H, Tanaka Y, Maekawa T, Nakafuku M, Ishii S: Sonic Hedgehoginduced activation of the Gli1 promoter is mediated by GLI3. J. Biol. Chem. 1999; 274: $8143-8152$

[35] García-García MJ, Eggenschwiler JT, Caspary T, Alcorn HL, Wyler MR, Huangfu D, Rakeman AS, Lee JD, Feinberg EH, Timmer JR, Anderson KVAnalysis of mouse embryonic patterning and morphogenesis by forward genetics. Proc Natl Acad Sci U S A. 2005 Apr 26; 102(17): 5913-9

[36] Huangfu D, Anderson KV. Cilia and Hedgehog responsiveness in the mouse. Proc Natl Acad Sci U S A. 2005; Aug 9; 102(32):11325-30

[37] Echelard Y, Epstein D J, St-Jacques B, Shen L, Mohler J., McMahon J A. et al: Sonic hedgehog, a member of a family of putative signaling molecules, is implicated in the regulation of CNS polarity. Cell 1993; 75: $1417-1430$ 
[38] Huangfu D, Anderson K V: Signaling from Smo to Ci/Gli: conservation and divergence of Hedgehog pathways from Drosophila to vertebrates. Development. 2006; 133: 314

[39] Huangfu D, Liu A, Rakeman A S, Murcia N S, Niswander L, Anderson K V: Hedgehog signalling in the mouse requires intraflagellar transport proteins. Nature 2003; 426: 83-87.

[40] Liu A, Wang B, Niswander LA: Mouse intraflagellar transport proteins regulate both the activator and repressor functions of Gli transcription factors. Development. 2005; 132: 3103-3111

[41] May S R, Ashique A M, Karlen M, Wang B, Shen Y, Zarbalis K, et al.: Loss of the retrograde motor for IFT disrupts localization of Smo to cilia and prevents the expression of both activator and repressor functions of Gli. Dev. Biol. 2005; 287: 378-389.

[42] Zhang Q, Murcia N S, Chittenden L R, Richards W G, Michaud E J, Woychik R P, et al.: Loss of the Tg737 protein results in skeletal patterning defects. Dev. Dyn. 2003; 227: 78-90.

[43] Tanabe Y, Jessell T M: Diversity and pattern in the developing spinal cord. Science 1996; 274:1115 -1123.

[44] Briscoe J, Pierani A, Jessell T M, Ericson J: A homeodomain protein code specifies progenitor cell identity and neuronal fate in the ventral neural tube. Cell 2000; 101: $435-445$.

[45] Litingtung Y, Chiang C: Specification of ventral neuron types is mediated by an antagonistic interaction between Shh and Gli3. Nat. Neurosci 2000; 3: 979-985.

[46] Wijgerde M, McMahon J A, Rule M, McMahon A P: A direct requirement for Hedgehog signaling for normal specification of all ventral progenitor domains in the presumptive mammalian spinal cord. Genes Dev. 2002; 16: 2849 -2864.

[47] Bai C B, Stephen D, Joyner A L: All mouse ventral spinal cord patterning by hedgehog is Gli dependent and involves an activator function of Gli3. Dev. Cell 2004; 6:103 115.

[48] Lei Q, Jeong Y, Misra K, L, S, Zelman A K, Epstein D J, Matise M P: Wnt signaling inhibitors regulate the transcriptional response to morphogenetic Shh-Gli signaling in the neural tube. Dev. Cell 2006); 11:325 -337

[49] Fuccillo M, Joyner A L, Fishell G: Morphogen to mitogen: the multiple roles of hedgehog signalling in vertebrate neural development. Nat. Rev. Neurosci. 2006; 7: $772-783$

[50] Huangfu D, Anderson KV. Cilia and Hedgehog responsiveness in the mouse. Proc Natl Acad Sci U S A. 2005 Aug 9;102 (32):11325-30.

[51] Buxton P, Francis-West P H, Davey M G, Tickle C, Paton I R, Morrice D R, et al: Craniofacial development in the talpid3 chicken mutant. Differentiation 2004; 72: $348-362$

[52] Chiang C, Litingtung Y, Lee E, Young K E, Corden J L, Westphal H, et al: Cyclopia and defective axial patterning in mice lacking Sonic hedgehog gene function. Nature 1996; 383,407 -413.

[53] Cole F, Krauss R S: Microform holoprosencephaly in mice that lack the Ig superfamily member Cdon. Curr. Biol. 2003; 13: 411 -415 
[54] Concordet J P, Lewis K E, Moore J W, Goodrich L V, Johnson R L, Scott M P, et al: Spatial regulation of a zebrafish patched homologue reflects the roles of sonic hedgehog and protein kinase $\mathrm{A}$ in neural tube and somite patterning. Development. 1996; 122: 2835 -2846

[55] Cooper A F, Yu K P, Brueckner M, Brailey L L, Johnson L, McGrath J M, et al. Cardiac and CNS defects in a mouse with targeted disruption of suppressor of fused. Development. 2005; 132: 4407 -4417.

[56] Kondo S, Sato-Yoshitake R, Noda Y, Aizawa H, Nakata T, Matsuura Y, et al: KIF3A is a new microtubule-based anterograde motor in the nerve axon. J. Cell Biol. 1994; 125 : $1095-1107$

[57] Cai C, Thorne J, Grabel L.: Hedgehog serves as a mitogen and survival factor during embryonic stem cell neurogenesis. Stem Cells.2008 May; 6(5):1097-108.

[58] Bambakidis NC, Horn EM, Nakaji P, Theodore N, Bless E, Dellovade T, et al: Endogenous stem cell proliferation induced by intravenous hedgehog agonist administration after contusion in the adult rat spinal cord. J Neurosurg Spine. 2009 Feb; 10(2):171-6.

[59] Han Y-G, Spassky N, Romaguera Rosa M, Garcia-Verdugo JM, Aguilar A, SchneiderMaunoury S, et al.: Hedgehog signaling and primary cilia are required for the formation of adult neural stem cells. Nat Neurosci. 2008; 11(3):277-84.

[60] Ekker S C, Ungar A R, Greenstein P, von Kessler D P, Porter J A, Moon R T, et al: Patterning activities of vertebrate hedgehog proteins in the developing eye and brain. Curr. Biol. 1995; 5: 944-955

[61] Spassky N, Han Y-G, Aguilar A, Strehl L, Besse L, Laclef C, et al: A Primary Cilia are required for cerebellar development and Shh-dependent expansion of progenitor pool Dev Biol. 2008; 317(1): 246-59

[62] Savage JJ, Casey JN, McNeill IT, Sherman JH. Neurenteric cysts of the spine. J. Craniovertebr Junction Spine. 2010 Jan; 1(1): 58-63

[63] Huangfu D, Anderson KV: Signaling from Smo to Ci/Gli: conservation and divergence of Hedgehog pathways from Drosophila to vertebrates. Development. 2006 Jan; 133(1):3-14.

[64] Schermer B, Ghenious C, Bartram M, Mueller RU, Kotsis F, Hoehne M, et al: The von Hippel- Lindau tumor suppressor protein controls ciliogenesis by orienting microtubule growth. J. Cell Biol. 2006;175 : 547 - 554

[65] Saran A. Basal cell carcinoma and the carcinogenic role of aberrant Hedgehog signaling. Future Oncol. 2010 Jun; 6(6):1003-14

[66] Romé P, Prigent C, Giet R. Centrosomes, mitotic spindle and cancer: find the odd one out! Med Sci (Paris). 2010 Apr; 26(4): 377-83.

[67] Saqui-Salces M, Merchant JL. Hedgehog signaling and gastrointestinal cancer. Biochim Biophys Acta. 2010 Jul; 1803(7):786-95.

[68] Yagyuu T, Kirita T, Sasahira T, Moriwaka Y, Yamamoto K, Kuniyasu H. Recurrence of keratocystic odontogenic tumor: clinicopathological features and immunohistochemical study of the Hedgehog signaling pathway. Pathobiology. 2008; 75(3):171-6.

[69] Gerdes JM, Katsanis N. Ciliary Function and Wnt Signal Modulation. Current Topics in Developmental Biology 2008; Volume 85:176-191 
[70] Dejana E. The role of wnt signaling in physiological and pathological angiogenesis. Circ Res. 2010 Oct 15;107(8):943-52

[71] Rao TP, Kühl M. An updated overview on Wnt signaling pathways: a prelude for more. Circ Res. 2010 Jun 25;106 (12):1798-806.

[72] Yu W, McDonnell K, Taketo MM, Bai CB. Wnt signaling determines ventral spinal cord cell fates in a time-dependent manner. Development. 2008 Nov; 135(22):3 687-96

[73] Afzelius BA. Cilia-related diseases. J. Pathol. 2004; 204 : 470- 477.

[74] Badano JL, Mitsuma N, Beales PL, Katsanis N. The ciliopathies: an emerging class of human genetic disorders. Annu. Rev. Genomics Hum. Genet. 2006; 7: 125-148.

[75] Fliegauf M, Benzig T, Omran H. When cilia go bad: cilia defects and ciliopathies. Nat. Rev. Mol. Cell Biol. 2007; 8 : 880 - 893 .

[76] D'Angelo A, Franco B. The dynamic cilium in human diseases. PathoGenetics 2009, 2:3:1-15

[77] Inglis P, Noroevich KA, Leroux MR. Piecing together a ciliome. Trends Genet. 2006; 22 : 491- 500.

[78] Marshall WF: The cell biological basis of ciliary disease. The Journal of Cell Biology, 2008; Vol. 180, No. 1, January 14, 17-21

[79] McGrath J, Brueckner M. Cilia are at the heart of vertebrate left-right asymmetry. Curr Opin Genet Dev 2003; 13:385-392

[80] McGrath J, Somlo S, Makova S, et al. Two populations of node monocilia initiate leftright asymmetry in the mouse. Cell 2003; 114:61-73.

[81] Nonaka S, Shiratori H, Saijoh Y, et al. Determination of left-right patterning of the mouse embryo by artificial nodal flow. Nature 2002; 418: 96-99

[82] Berdon WE, Willi U. Situs inversus, bronchiectasis, and sinusitis and its relation to immotile cilia: history of the diseases and their discoverers-Manes Kartagener and Bjorn Afzelius. Pediatr Radiol 2004; 34:38-42

[83] Afzelius BA: A human syndrome caused by immotile cilia. Science 1976, 193:317-319.

[84] Zariwala MA, Knowles MR, Omran H: Genetic defects in ciliary structure and function. Annu Rev Physiol 2007; 69: 423-450.

[85] Bartoloni L, Dombi V, O'Rawe A, Walne A, Chung E, Afzelius BA, et al. Primary ciliary dyskinesia: a genome-wide linkage analysis reveals extensive locus heterogeneity. Eur J Hum Genet 2000; 8: 109-118

[86] Davy BE, Robinson M.L. Congenital hydrocephalus in hy3 mice is caused by a frameshift mutation in Hydin, a large novel gene. Hum. Mol. Genet. 2003; 12 : 1163 $-1170$

[87] Lechtreck KF, Witman GB. Chlamydomonas reinhardtii hydin is a central pair protein required for fl agellar motility. J. Cell Biol. 2007; $176: 473$ - 482

[88] Murga-Zamalloa CA, Swaroop A, Khanna H. RPGR-containing protein complexes in syndromic and non-syndromic retinal degeneration due to ciliary dysfunction. J Genet. 2009 Dec; 88(4): 399-407.

[89] Fain GL, Hardie R, Laughlin SB. Phototransduction and the evolution of photoreceptors. Curr Biol. 2010 Feb 9; 20(3): R114-24.

[90] Wilson PD. Polycystic kidney disease. N Engl J Med 2004; 350: 151-164.

[91] Simons M, Gloy J, Ganner A, Bullerkotte A, Bashkurov M, Kronig C, et al. Inversin, the gene product mutated in nephronophthisis type II, functions as a molecular switch between Wnt signaling pathways. Nat. Genet. 2005; 37: 537-543. 
[92] Barr MM, DeModena J, Braun D, Nguyen CQ, Hall D.H, Sternberg P.W . The Caenorhabditis elegans autosomal dominant polycystic kidney disease gene homologs lov-1 and pkd-2 act in the same pathway. Curr. Biol. 2001; $11: 1341$ 1346.

[93] Hughes J, Ward CJ, Peral B, et al. The polycystic kidney disease 1 (PKD1) gene encodes a novel protein with multiple cell recognition domains. Nat Genet 1995; 10:151-160

[94] Mochizuki T, Wu G, Hayashi T, et al. PKD2, a gene for polycystic kidney disease that encodes an integral membrane protein. Science 1996; 272: 1339-1342

[95] Yoder BK,. Hou X, Guay-Woodford LM. The polycystic kidney disease proteins, polycystin-1, polycystin-2, polaris, and cystin, are colocalized in renal cilia. J. Am. Soc. Nephrol. 2002; 13 : 2508 - 2516

[96] Fischer E, Legue E, Doyen A, Nato F, Nicolas J F, Torres V, et al: Defective planar cell polarity in polycystic kidney disease. Nat. Genet. 2006; 38, 21-23.

[97] Lee JH, Gleeson JG: The role of primary cilia in neuronal function. Neurobiol Dis. 2010 May; 38(2):167-72

[98] Green JA, Mykytyn K. Neuronal ciliary signaling in homeostasis and disease. Cell Mol Life Sci. 2010 Oct; 67(19): 3287-97

[99] Nachury MV, Loktev AV, Zhang Q, Westlake CJ, Peranen J, Merdes A, et al.: A core complex of BBS proteins cooperates with the GTPase Rab8 to promote ciliary membrane biogenesis. Cell. 2007; 129 : 1201 - 1213 
NEUROIMAGING FOR

\section{CLINICIANS}

COMBINING RESEARCH AND PRACTICE

tanes by fulio F. . Peres

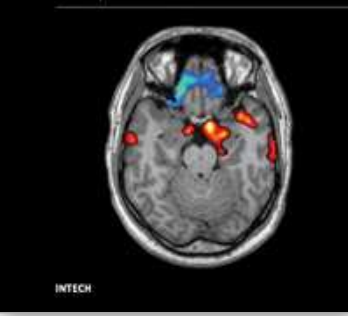

\section{Neuroimaging for Clinicians - Combining Research and Practice}

Edited by Dr. Julio F. P. Peres

ISBN 978-953-307-450-4

Hard cover, 424 pages

Publisher InTech

Published online 09, December, 2011

Published in print edition December, 2011

Neuroimaging for clinicians sourced 19 chapters from some of the world's top brain-imaging researchers and clinicians to provide a timely review of the state of the art in neuroimaging, covering radiology, neurology, psychiatry, psychology, and geriatrics. Contributors from China, Brazil, France, Germany, Italy, Japan, Macedonia, Poland, Spain, South Africa, and the United States of America have collaborated enthusiastically and efficiently to create this reader-friendly but comprehensive work covering the diagnosis, pathophysiology, and effective treatment of several common health conditions, with many explanatory figures, tables and boxes to enhance legibility and make the book clinically useful. Countless hours have gone into writing these chapters, and our profound appreciation is in order for their consistent advice on the use of neuroimaging in diagnostic work-ups for conditions such as acute stroke, cell biology, ciliopathies, cognitive integration, dementia and other amnestic disorders, Post-Traumatic Stress Disorder, and many more

\section{How to reference}

In order to correctly reference this scholarly work, feel free to copy and paste the following:

Carmen Carrascosa Romero, José Luis Guerrero Solano and Carlos De Cabo De La Vega (2011).

Ciliopathies: Primary Cilia and Signaling Pathways in Mammalian Development, Neuroimaging for Clinicians Combining Research and Practice, Dr. Julio F. P. Peres (Ed.), ISBN: 978-953-307-450-4, InTech, Available from: http://www.intechopen.com/books/neuroimaging-for-clinicians-combining-research-andpractice/ciliopathies-primary-cilia-and-signaling-pathways-in-mammalian-development

\section{INTECH}

open science | open minds

\section{InTech Europe}

University Campus STeP Ri

Slavka Krautzeka 83/A

51000 Rijeka, Croatia

Phone: +385 (51) 770447

Fax: +385 (51) 686166

www.intechopen.com

\section{InTech China}

Unit 405, Office Block, Hotel Equatorial Shanghai

No.65, Yan An Road (West), Shanghai, 200040, China

中国上海市延安西路65号上海国际贵都大饭店办公楼 405 单元

Phone: +86-21-62489820

Fax: $+86-21-62489821$ 
(C) 2011 The Author(s). Licensee IntechOpen. This is an open access article distributed under the terms of the Creative Commons Attribution 3.0 License, which permits unrestricted use, distribution, and reproduction in any medium, provided the original work is properly cited. 